\title{
Tolerancia y quimerismo en el trasplante hepático
}

\author{
J. A. Pons Miñano, P. Ramírez Romero ${ }^{1}$, R. Robles Campos $^{1}$, F. Sánchez Bueno y P. Parrilla Paricio \\ Servicio de Aparato Digestivo. ${ }^{~}$ Departamento de Cirugía General. Unidad de Trasplante Hepático. Hospital \\ Universitario Virgen de la Arrixaca. Murcia
}

Pons Miñano JA, Ramírez Romero P, Robles Campos $R$, Sánchez Bueno F, Parrilla Paricio P. Tolerancia y quimerismo en el trasplante hepatico. Rev Esp Enferm Dig 2007; 99: 343-350.

\section{INTRODUCCIÓN}

Los avances en el tratamiento inmunosupresor han tenido un gran impacto en la evolución y en el éxito de los trasplantes de órganos y en particular del trasplante hepático. Con la introducción de los nuevos fármacos inmunosupresores, la incidencia de rechazo agudo ha disminuido de forma considerable, y la supervivencia de los pacientes trasplantados hepáticos es del 83 y del $70 \%$ al año y 5 años respectivamente (1). Sin embargo, la toxicidad asociada con el uso de estos fármacos es importante, condicionando la aparición de hipertensión arterial, hiperlipemia, diabetes, insuficiencia renal y tumores de novo en los pacientes trasplantados $(2,3)$. Por todo ello, y para mejorar la eficacia y la especificidad de los tratamientos inmunosupresores, es imprescindible profundizar en el conocimiento de los mecanismos de la respuesta alogénica primaria contra antígenos extraños y en los mecanismos de tolerancia específica de antígeno, para que nos pueda ayudar a evitar o disminuir al máximo posible el uso de fármacos inmunosupresores.

Es un hecho conocido que el trasplante hepático entre especies animales como el cerdo y entre ciertas combinaciones de ratas y ratones, puede realizarse sin inmunosupresión (4-6). Esta observación en animales y la posibilidad de retirar completamente los fármacos inmunosupresores en pacientes seleccionados con tras-

Recibido: 19-02-07.

Aceptado: 27-02-07.

Correspondencia: J. A. Pons Miñano. Servicio de Aparato Digestivo. Unidad de Trasplante Hepático. Hospital Universitario Virgen de la Arrixaca. Ctra. Madrid-Cartagena, s/n. 30120 El Palmar. Murcia. e-mail: joseapons@yahooo.es plante hepático (7-10), nos permite afirmar que el hígado es un órgano inmunológicamente privilegiado (11), que puede tolerarse tras el trasplante con menor inmunosupresión y en ocasiones es posible retirar completamente los fármacos inmunosupresores (tolerancia operacional) (12). Datos experimentales apoyarían la idea de poder inducir tolerancia en humanos sometidos a trasplante de órganos. Aunque la tolerancia sería el objetivo ideal, la heterogeneidad de combinaciones posibles entre donante y receptor, el estado inmune del receptor, la enfermedad de base del paciente trasplantado, y las consecuencias imprevisibles de las infecciones hacen que una tolerancia estable sea extremadamente difícil en todos los pacientes (13).

La tolerancia en el ámbito del trasplante sería la falta de respuesta inmune a los aloantígenos (antígenos extraños) del órgano trasplantado, en ausencia de inmunosupresión (14). El fenómeno de tolerancia inmunológica es la ausencia de respuesta a un antígeno con el que ha habido un encuentro propio, y es por tanto, un fenómeno activo (15). La tolerancia a antígenos propios, al igual que la tolerancia a los aloantígenos es una función del sistema inmune. Los mecanismos implicados en la tolerancia a los órganos trasplantados son complejos y no totalmente conocidos. El objetivo de esta revisión es describir los mecanismos implicados en la tolerancia, en especial en el ámbito del trasplante hepático, destacando el papel del quimerismo celular y los fenómenos de inmunorregulación en el desarrollo de tolerancia.

\section{ALORRECONOCIMIENTO Y RECHAZO}

El sistema inmune funciona diferenciando lo propio de lo extraño. Concretamente, el término alorreconoci- 
miento expresa la capacidad de las células $\mathrm{T}$ para reconocer, entre miembros de la misma especie, polimorfismos genéticamente codificados a nivel de moléculas con capacidad antigénica como las del complejo mayor de histocompatibilidad (CMH o MHC en inglés). El rechazo del injerto se inicia mediante el reconocimiento del antígeno extraño del MHC expresado en el órgano trasplantado por parte de los linfocitos $\mathrm{T}$ del receptor. Ante un daño inflamatorio, como la propia cirugía y la isquemia que sufre el órgano trasplantado, las células presentadoras de antígeno (CPA o APC en inglés) y en especial las células dendríticas (DCs) (las células presentadoras de antígenos más importantes) donantes presentes en el injerto, maduran y emigran vía aferente o a través de la sangre a órganos linfoides de drenaje del injerto. Allí presentan péptidos alogénicos y MHC del donante a las células $\mathrm{T}$ alorreactivas preexistentes del receptor mediante lo que se conoce como vía directa de presentación antigénica $(16,17)$ (Fig. 1). Estas células T del receptor son en su mayoría, pero no exclusivamente, linfocitos CD4 (colaboradores) reactivos a los antígenos MHC de clase II (18). Otra vía de iniciación del rechazo es la llamada vía indirecta de presentación. En esta situación, las APC del receptor captan y procesan los antígenos MHC del donante y los presentan en el contexto del MHC del receptor a los linfocitos $\mathrm{T}$ del receptor (19) (Fig. 1). Es posible que la ruta indirecta de presentación antigénica suponga un débil estímulo para el rechazo, dado que la eliminación de las DC donantes del injerto, que eliminaría la vía directa de presentación, es suficiente para prevenir el rechazo (16). Posiblemente la vía directa predomine en el postrasplante inmediato, siendo el factor más importante del rechazo agudo, dada la rápida migración de las DC del injerto expresando antígenos del donante a los órganos linfoides secunda-

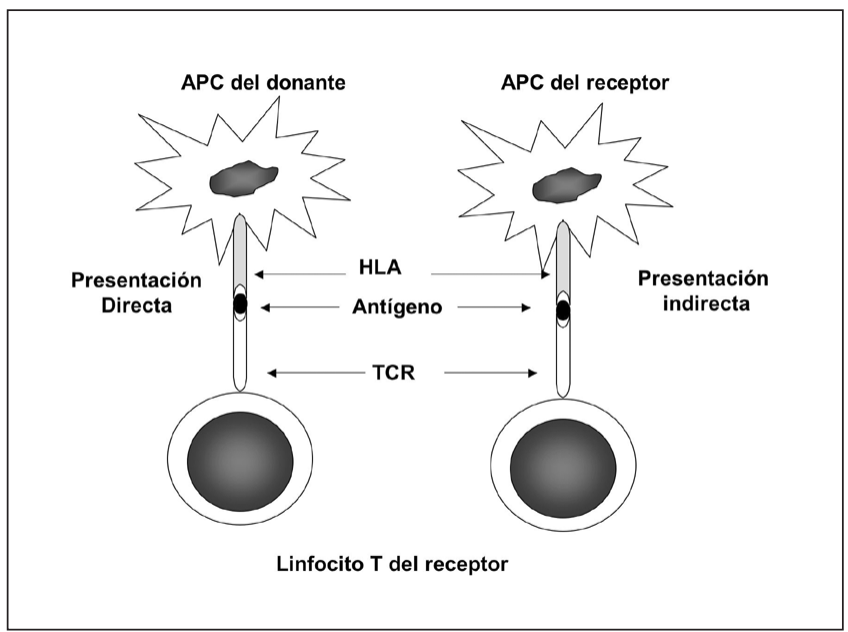

Fig. 1. Vías de presentación directa e indirecta de los antígenos. En la presentación directa, el antígeno es presentado en el contexto HLA de la célula presentadora (APC) del donante, mientras que en la presentación indirecta, el antígeno es presentado por la APC del receptor en el contexto del HLA del receptor. rios, donde encuentran los linfocitos $\mathrm{T}$ aloespecíficos (20). La vía indirecta de presentación probablemente se desencadena por los antígenos que salen del órgano trasplantado, o en el caso del hígado, por las moléculas MHC clase I, captadas y presentadas por las propias DC. Así, mientras la vía directa de presentación es importante para iniciar el rechazo agudo, la vía indirecta podría ser importante para sostener una respuesta persistente a los aloantígenos y participar en el mecanismo del rechazo crónico (21). Al mismo tiempo, es posible que la vía indirecta esté implicada en los fenómenos de inmunorregulación, dado que las células $\mathrm{T}$ aloespecíficas muestran propiedades reguladoras a través de la inhibición de la producción de interferón (IFN)- $\gamma$ en pacientes con trasplante renal (22).

El linfocito T tiene la capacidad de recibir estímulos, procesarlos y enviarlos al núcleo a través de señales de transducción de la activación intracelular. Estas señales modifican lípidos intracelulares que inician una vía que finaliza en la activación y translocación al núcleo de factores de transcripción que regulan la activación y expresión de genes (23).

Los linfocitos $\mathrm{T}$ reciben tres tipos distintos de señales coordinadas para activarse (Fig. 2). La señal primaria o señal 1 se produce por el contacto del complejo MHC/alopéptido en las APC, con el receptor de la célula T (TCR) (11). La segunda señal o señal 2 (coestimuladora) se produce por la interacción de las moléculas coestimuladoras a nivel del linfocito $\mathrm{T}$ y sus ligandos sobre las APC, y de este modo la célula T puede diferenciarse a célula efectora CD4 (capaz de liberar citoquinas proinflamatorias) o CD8 (con capacidad citotóxica) (24). Ade-

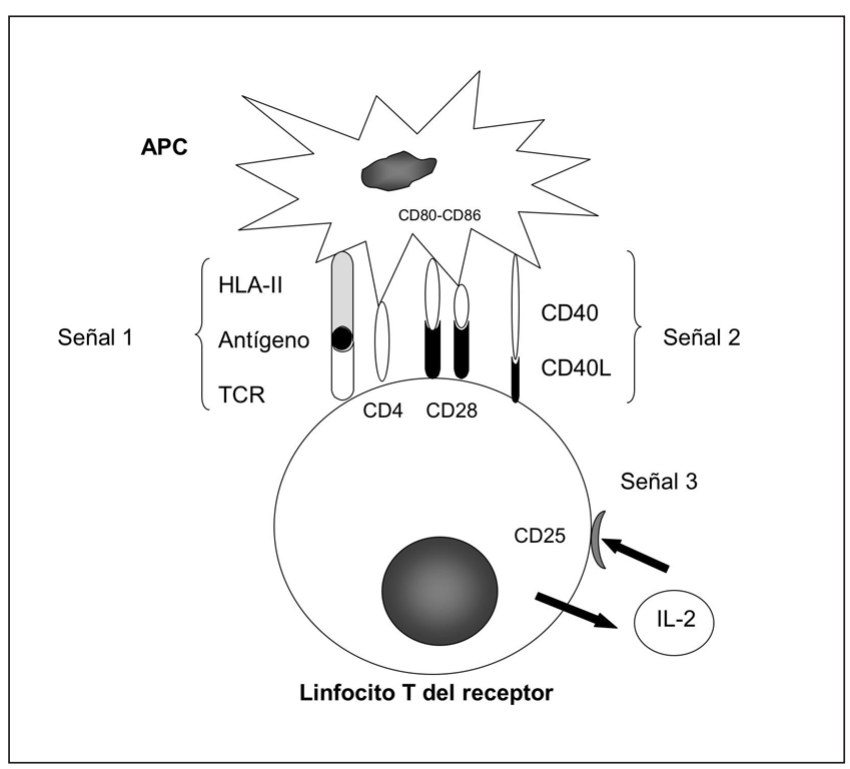

Fig. 2. Señales de activación del linfocito T. Después de la presentación del antígeno en una molécula de HLA por la APC al TCR del linfocito (señal 1), se desencadenan señales de coestimulación (señal 2) produciéndose IL-2 que estimula su receptor CD25 (señal 3), proliferando los linfocitos T. 
más deben participar señales terciarias (señal 3) mediadas por citoquinas como la interleuquina 2 (IL-2) que son indispensables para la proliferación y diferenciación hacia células efectoras y la generación de células de memoria, así como quimiocinas que guían la migración a los órganos linfoides secundarios (bazo y ganglios linfáticos) (25). La señal 1 en ausencia de señal 2 coestimuladora, como ocurre en el hígado frecuentemente, da lugar a un estado de falta de respuesta de los linfocitos T, o anergia, en el que las células $\mathrm{T}$ reconocen los antígenos a través del TCR pero no pueden responder ante un nuevo contacto con el antígeno. Por este motivo se han realizado múltiples estudios dirigidos a bloquear la señal coestimuladora para prolongar la supervivencia de los injertos.

Las señales coestimuladoras entre linfocitos T y APC están mediadas por dos grupos moleculares principalmente: grupo I: superfamilia de la inmunoglobulinas (CD28/CD80-CD86, CTLA4/CD80-CD86, ICOS/ICOSL, PD1/PD11); y grupo II: superfamilia de receptores del TNF (CD40/CD40L, OX40/OX40L, 4-1BB/4-1BB-L, RANKL/TRANCE y LIGHT/LIGHT-L).

Las dos señales coestimuladoras más conocidas e importantes son las formadas por CD28 y CD40. La molécula CD28 se expresa en los linfocitos CD4 y CD8 y su ligando B7-1 (CD80) y B7-2 (CD86) se expresa en diversas APC (DC, linfocitos T, y macrófagos). Mediante esta señal aumenta la producción de IL-2, se produce proliferación de los linfocitos y se inducen proteínas antiapoptóticas (26). La molécula CTLA-4 (cytotoxic T lymphocyte associated antigen 4) es una proteína relacionada con CD28 que se expresa en los linfocitos T activados y, como CD28, se une a CD80 y CD86, pero produciendo una señal negativa que atenúa la función de los linfocitos T (26).

La coestimulación a través de CD40, expresado en las APC y CD40-L o CD154, expresado en los linfocitos T, linfocitos $\mathrm{B}$ y células NK (natural killer), es crítica en la respuesta inmune a los aloantígenos. Este tipo de coestimulación CD40/CD154, aumenta la función de APC, con un aumento en la expresión de MHC clase II, CD80 y CD86, así como un aumento en la producción de citoquinas como IL-12 (27).

Cuando los linfocitos $\mathrm{T}$ reciben las señales de estimulación y coestimulación se produce la lesión del injerto fundamentalmente por los linfocitos T citotóxicos (CD8+) que producen la apoptosis celular en el injerto. En el rechazo del injerto hepático, la apoptosis mediada por la vía perforina/granzima (28) es uno de los mecanismos de rechazo mas importantes junto a la vía Fas/Fas ligando (29), ambos mecanismos inducidos por las células T citotóxicas.

\section{EL HÍGADO COMO ÓRGANO INMUNE PRIVILEGIADO}

La estructura del hígado tiene profundas implicaciones para su función inmune. El hígado está expuesto continuamente a grandes cantidades de antígenos que llegan fundamentalmente a través del sistema portal. Aproximadamente un $30 \%$ de la sangre total pasa por el hígado cada minuto, transportando al hígado cerca de $10^{8}$ linfocitos periféricos en 24 horas (30).

El hígado, por sus propiedades anatómicas e inmunológicas es un lugar donde los antígenos del tracto gastrointestinal y los aloantígenos, cuando se trata de un hígado trasplantado, son presentados por una compleja red de células sinusoidales y APC a los linfocitos. La población de linfocitos hepáticos es rica en NK y NKT (natural killer $T$ cells) jugando un papel crítico como primera defensa contra los patógenos, modulando la lesión hepática y el reclutamiento de linfocitos circulantes. Recientemente se ha podido documentar la existencia de un porcentaje alto de linfocitos no convencionales en el hígado, que raramente se presentan el sangre periférica, incluyendo NK, NKT expresando el TCR $\gamma \delta$ (célula T $\gamma \delta$ y V $\alpha 24 J \alpha Q$ TCR) y DC. Estas células NKT $\gamma \delta$ tienen propiedades inmunorreguladoras y parecen reconocer CD1d, expresado en la superficie de las APC (células de Kupffer) y en los hepatocitos (31). Las células NK (CD3-CD16+CD56+), representan hasta un $45 \%$ de los linfocitos hepáticos, mientras que sólo suponen un 5 al 15\% de las células mononucleares periféricas. Estas células NK parecen liberar señales negativas hacia los linfocitos $\mathrm{T}$ del receptor cuando migran al hígado después del trasplante hepático, contribuyendo a la tolerancia del injerto hepático.

El contexto en el que se presentan los antígenos en el hígado a los linfocitos $\mathrm{T}$ favorece un ambiente tolerogénico. Este incluye la naturaleza de las APC del hígado donante, de la presencia o ausencia de moléculas coestimuladoras y del microambiente de citoquinas. En particular, las APC hepáticas tienen una capacidad constitutiva de inducir respuestas tolerogénicas en los linfocitos T (32).

Las células endoteliales sinusoidales hepáticas (CESH) tienen un fenotipo único que expresa marcadores típicos de células de tipo mieloide (CD1,CD4,CD11c). Dichas CESH tienen parecido con DC inmaduras, constituyendo un nuevo tipo de APC órgano-específica. Los linfocitos CD4+ activados por las CESH son incapaces de diferenciarse hacia células Th1 (productoras de IL-2), y expresan altos niveles de la IL-10 inmunosupresora (33). Además los linfocitos CD8+ estimulados por las CESH no pueden responder a nuevas estimulaciones antigénicas (32).

Diversos estudios han planteado la cuestión sobre la renovación de las células endoteliales en los órganos trasplantados y su relación con la tolerancia o el rechazo. El recambio endotelial se ha demostrado en corazón (34), riñones (35), y en el hígado (36) trasplantado. Laggij y cols. (35) demostraron que tras el trasplante renal, el recambio endotelial de las células endoteliales del donante por células endoteliales del receptor se correlacionaban con rechazo vascular. Se ha propuesto que en el hígado trasplantado, el recambio endotelial por células endoteliales del donante procedentes de células de médula ósea, podría favorecer la tolerancia del injerto $(36,37)$. Sin em- 
bargo se pudo demostrar posteriormente, que el quimerismo endotelial en el injerto hepático no se relaciona con la inducción de tolerancia en los pacientes trasplantados hepáticos después de la retirada completa de inmunosupresión (9).

Recientemente, se demostró que la capacidad del hígado de inducir tolerancia se debe, en parte, a la capacidad de activación in situ de los linfocitos T. Es conocida la capacidad de los hepatocitos como células presentadoras de antígenos tolerogénicas. En contra del dogma que establece que los linfocitos $\mathrm{T}$ nä̈ve no pueden interactuar con células parenquimatosas fuera de órganos linfoides, se ha podido observar que los linfocitos intrahepáticos y los linfocitos CD8+ naïve circulantes pueden interactuar con los hepatocitos a través de extensiones citoplasmáticas que pueden penetrar las fenestraciones de las CESH (38) (Fig. 3). Esta activación local de los linfocitos T por medio de los hepatocitos concede un papel importante a los hepatocitos como APC y da lugar al desarrollo de tolerancia dentro del hígado (39).

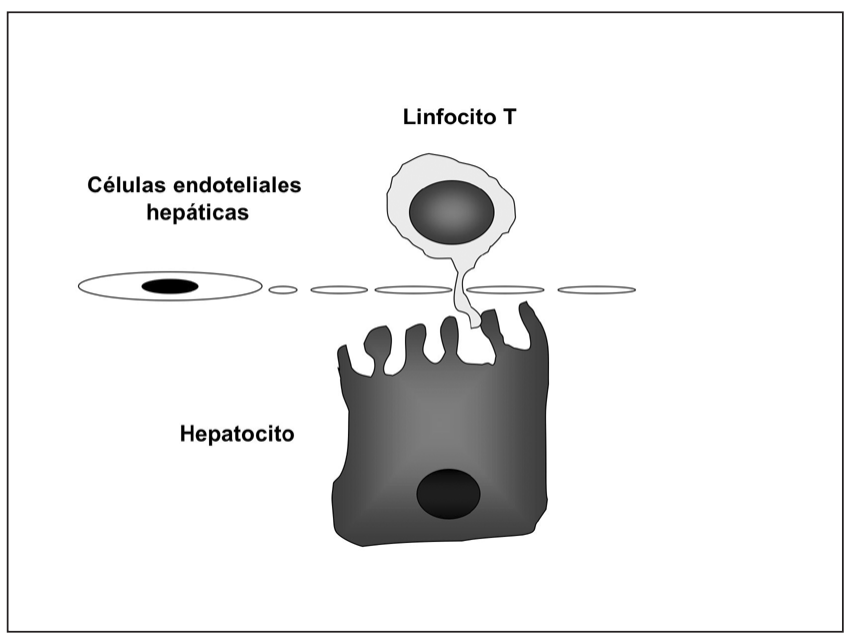

Fig. 3. Contacto de los linfocitos T con los hepatocitos, por medio de extensiones citoplasmáticas que atraviesan las fenestraciones de las células endoteliales sinusoidales.

\section{EL FENÓMENO DE LA TOLERANCIA DEL INJERTO HEPÁTICO}

Diversas observaciones experimentales y a nivel clínico indican que el hígado es "menos inmunogénico" que otros órganos vascularizados, y que el injerto hepático puede inducir propiedades tolerogénicas a otros órganos.

Un fenómeno inusual en otros órganos trasplantados es la tolerancia espontánea del injerto hepático en ciertas especies como el ratón, la rata y el cerdo en ausencia de inmunosupresión (40-42), a pesar de una estimulación inicial del sistema inmune (15). Además el hígado trasplantado puede actuar como inmunosupresor cuando se trasplanta a animales con rechazo después de un trasplante de páncreas o corazón, revirtiendo dicho rechazo $(43,44)$.

El injerto hepático en humanos es menos susceptible al rechazo humoral (45) y no requiere compatibilidad MHC entre donante y receptor (46). El trasplante hepático protege habitualmente al riñon trasplantado del mismo donante, del rechazo agudo humoral y celular (47). En pacientes trasplantados hepáticos seleccionados es posible retirar definitivamente toda la inmunosupresión hasta en un 25-30\% de casos (7-10), permaneciendo sanos en algunos casos hasta 30 años después de la retirada, lo que viene considerándose una tolerancia "operacional" (12).

La existencia de tolerancia en modelos animales y en humanos después del trasplante hepático, ha llevado a utilizar dichos modelos en la investigación de los mecanismos intrínsecos de tolerancia.

\section{MECANISMOS DE TOLERANCIA EN EL TRASPLANTE HEPÁTICO}

Aunque los mecanismos exactos que establecen y mantienen la tolerancia de los órganos trasplantados no son bien conocidos, los distintos estudios de tolerancia en animales, y menos en humanos, demuestran que la tolerancia es un proceso activo y altamente regulado. El proceso de activación inmune (proliferación y diferenciación de linfocitos) ocurre normalmente como una respuesta inmune al injerto hepático. Este proceso natural de respuesta puede resultar en dos vías de comportamiento distintas (Fig. 4): a) una vía (o grupo de vías) inmune dirigido a la destrucción del injerto (vía del rechazo); y b) una vía (o grupo de vías) orientada hacia la tolerancia (vía tolerogénica). Este paradigma dualístico postula la existencia de mecanismos comunes inducidos por el injerto hepático que dan lugar a rechazo o tolerancia, dependiendo

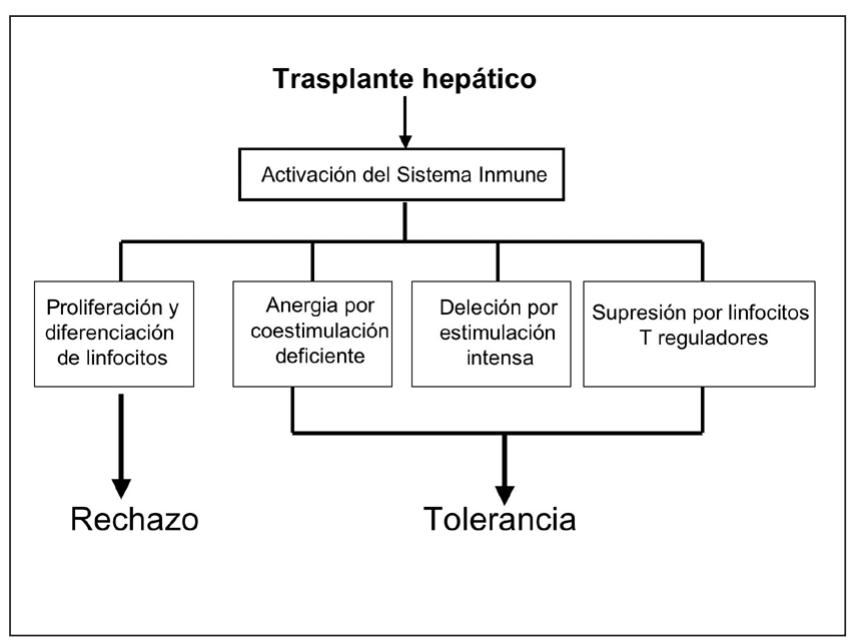

Fig. 4. Mecanismos de rechazo y tolerancia en el trasplante de órganos. 
del balance cuantitativo entre ambas vías (15). Los mecanismos inmunes exactos que subyacen la vía de la tolerancia no son totalmente conocidos, pero pueden incluir los siguientes fenómenos (48): a) deleción por apoptosis clonal de linfocitos $\mathrm{T}$ específicos de donante (tolerancia central o periférica); y b) tolerancia periférica (regulación, anergia por coestimulación deficiente, deleción por activación repetida).

\section{TOLERANCIA CENTRAL}

Los fenómenos de tolerancia central se desarrollan fundamentamente en el timo. Las células precursoras de los linfocitos $\mathrm{T}$ procedentes de las stem cell de la médula ósea maduran en el timo y aprenden a distinguir lo propio de lo extraño. Durante el proceso de diferenciación de las células $\mathrm{T}$, los precursores linfoides CD4-CD8- se convierten en células $\mathrm{T}$ doble positivas CD4+CD8+ y posteriormente en $\mathrm{CD} 4+\mathrm{TCR}+$ si se presentaron a moléculas HLA de clase II o CD8+TCR+ si se presentaron a moléculas HLA de clase I. Cuando la unión del linfocito T al complejo péptido-moléculas HLA presentado por las células epiteliales tímicas se realiza con un TCR linfocitario de baja afinidad se produce la llamada "selección positiva", que permite la supervivencia de dichos linfocitos que pasan al torrente circulatorio para colonizar los órganos linfoides secundarios. Por el contrario, los linfocitos con receptores que se unen con alta afinidad a estos complejos, experimentan muerte celular por apoptosis (selección negativa) (49). Algunos linfocitos autorreactivos escapan a la periferia y por este motivo es necesario contemplar la existencia de mecanismos reguladores naturales periféricos que puedan controlar este tipo de autorreactividad. Estos mecanismos reguladores han recobrado una relevancia fundamental en la investigación del trasplante y la autoinmunidad, y están mediados por células $\mathrm{T}$ reguladoras y células dendríticas tolerogénicas.

En modelos murinos existen dos aproximaciones experimentales que pueden generar tolerancia central muy estable, bien mediante trasplante alogénico de timo o bien mediante trasplante de médula ósea, pero ambas estrategias son de difícil aplicación clínica.

Con el trasplante alogénico de timo fetal o neonatal en un receptor que se ha timectomizado y deplecionado de células T CD4 y CD8, el receptor queda a merced de las células $\mathrm{T}$ que se generan de novo y que son capaces de reconocer lo propio y lo alogénico, impidiéndose el rechazo de un injerto alogénico del mismo haplotipo que el timo (50).

El fundamento de la estrategia de inducción de tolerancia mediante el trasplante de médula ósea se basa en el establecimiento de un quimerismo hematopoyético mixto. Cuando el timo del receptor se coloniza por DC del donante se produce un quimerismo central. Durante el proceso de diferenciación de las células $\mathrm{T}$ en el timo, las DC del donante, podrían participar en la purga de linfoci- tos T alorreactivos a través de selección negativa o deleción clonal y así generar un repertorio de células $\mathrm{T}$ tolerantes frente a lo propio y a los aloantígenos del donante (51). Sin embargo, si no se produce una deleción completa de linfocitos alorreactivos a través del quimerismo mixto después del trasplante de médula ósea, la posibilidad de rechazo, persiste, y la tolerancia sólo es posible si se desarrollan mecanismos inmunorreguladores que controlen dichos linfocitos $(52,53)$.

La aplicación clínica de los modelos animales de trasplante de médula ósea con protocolos de acondicionamiento con irradiación linfoide total, o con protocolos no mieloablativos con anticuerpos deplecionantes anti-CD4 y anti-CD40L o proteínas de fusión CTLA4-IG que inhiben la unión CD28 con CD80 o CD86, es difícil de establecer. Desde las primeras experiencias de Monaco y cols. (54) en trasplante renal, se han realizado diversos estudios en trasplante de hígado, páncreas, corazón y pulmón (55), pero sin conseguir tolerancia completa. Quedan por resolver todavía muchos problemas y en especial, se debe conseguir la depleción de las células alorreactivas periféricas que escapan a la deleción central tras la el quimerismo central conseguido con la transfusión de células de médula ósea (56).

\section{TOLERANCIA PERIFÉRICA. PAPEL DE LAS CÉLULAS REGULADORAS}

En los modelos de tolerancia espontánea del injerto hepático se produce precozmente una activación importante de los linfocitos del receptor a nivel de los órganos linfoides secundarios y una posterior deleción por agotamiento de los mismos (15). El estímulo es producido por la gran cantidad de leucocitos del donante que migran rápidamente a los tejidos linfoides y estimulan la producción de grandes cantidades de IL- 2 e IFN- $\gamma$ por parte de los linfocitos CD4 del receptor, agotándose y muriendo posteriormente por apoptosis (57).

Además de los mecanismos descritos de muerte celular inducida por activación, y otros mecanismos de tolerancia como la anergia o la desviación inmune o ignorancia, la presencia de células reguladoras parece jugar un papel central en los mecanismos de tolerancia hacia los órganos trasplantados (58). Se han identificado diversos subtipos de células $\mathrm{T}$ reguladoras: células $\mathrm{T}$ CD4+CD25+ supresoras, células $\mathrm{T}$ reguladoras tipo 1 (Tr1) productoras de IL-10, células Th3 productoras de "transforming growth factor- $\beta$-producing (TGF- $\beta$ ), células natural killer (NKT), CD8+CD28-CD27+ y CD4CD8- (12,59).

Los linfocitos $\mathrm{T}$ reguladores CD4+CD25+, junto a los NKT aparecen de forma espontánea en el timo, ejercen su actividad inmunorreguladora de forma innata y su efecto no parece ser antígeno-dependiente (60). Las células T reguladoras CD4+CD25+ fueron descritas por Sakaguchi y cols. en 1990 (61) observando que suponían el 5-15\% de las células CD4+ periféricas. Este tipo de células T regula- 
doras expresa también fenotipo de memoria (CD45RA${ }^{n e} \mathrm{CD} 45 \mathrm{RO}+\mathrm{CD} 45 \mathrm{RB}^{\text {low }}$ ), CTLA-4 o CD152 y GITR (glucocorticoid-induced tumor necrosis factor receptor). Recientemente se demostró que un marcador discriminativo de células $\mathrm{T}$ reguladoras CD4+CD25+ era el factor de transcripción Foxp3 (62). Las células $\mathrm{T}$ reguladoras CD4+CD25+ disminuyen la respuesta inmune alterando la respuesta $\mathrm{T}$ alogénica, la producción de anticuerpos, la secreción de citoquinas y la presentación antigénica (63). Este tipo de células reguladoras, además de inhibir la capacidad citolítica de los linfocitos $\mathrm{T}$ efectores, convierten otras células T respondedoras CD4+CD25- mediante contacto intercelular, a fenotipo regulador, amplificando el efecto supresor de las células reguladoras (tolerancia infecciosa) (64). Este tipo de linfocitos T reguladores inducidos en sangre periférica suprimen la respuesta alogénica a traves de mediadores solubles como la IL-10 y/o TGF- $\beta$.

$\mathrm{El}$ hecho de que las células $\mathrm{T}$ reguladoras CD4+CD25+ de sangre periférica de humanos sean capaces de suprimir la respuesta a aloantígenos (65), ha despertado interés en la generación de este tipo de células como una herramienta terapéutica que induzca tolerancia en trasplantes. Un ejemplo de ello sería estimular de forma repetitiva de células $\mathrm{T}$ nä̈ve con $\mathrm{DC}$ inmaduras, lo cual induce la producción de linfocitos $\mathrm{T}$ reguladores CD4+CD25+ (66).

Recientemente se ha podido observar en sangre periférica de los pacientes con trasplante hepático y tolerancia operacional (tolerancia sin inmunosupresión después de varios años con la misma) un incremento de células CD4+CD5 $+{ }^{\text {hight }}$ foxp3 $(67,68)$. Este hallazgo, junto a la mayor expresión de genes codificadores de células $\mathrm{T} \gamma \delta$, receptores NK y de proteínas involucradas en la finalización de proliferación (68) parece constituir una huella de los pacientes trasplantados hepáticos capaces de tolerar la retirada de inmunosupresión.

\section{CÉLULAS DENDRÍTICAS Y TOLERANCIA}

Las células dendríticas juegan un papel crucial en el establecimiento de tolerancia tanto central como periférica. En la periferia, las DC inducen tolerancia a través de la neutralización de linfocitos T reactivos (deleción, anergia, o inactivación). Además las DC inmaduras son capaces de inducir linfocitos $\mathrm{T}$ reguladores CD4+CD25+ de una forma antígeno-específica (69). La generación de DC tolerogénicas mediante diversas estrategias, como la utilización de rapamicina (70) podría inducir tolerancia, como se ha demostrado en modelos animales. Clásicamente se ha considerado la existencia de DC monocitoides (DC1) que inducen una respuesta Th1 (IL-2) y DC plasmocitoides (DC2) que inducen respuesta Th2 (IL-10) (71). En trasplantados hepáticos a los que se pudo retirar la inmunosupresión de forma definitiva, se observó que existía una proporción de precursores inmaduros de DC2 mayor que en los que no toleraban la retirada de inmuno- supresión (72), aunque este hallazgo no ha sido confirmado por otros autores (68).

\section{QUIMERISMO Y TOLERANCIA}

Quizás el inicio de la era moderna del trasplante, comienza con la demostración en 1943 por Medawar y Gibson que el rechazo de tejidos era una reacción inmune (73). Diez años después Billingham, Brent y Medawar (74) observan que tras el trasplante de leucocitos o de médula ósea en el embrión o recién nacido de ratón, con un sistema inmunológico inmaduro, desarrollaban quimerismo de leucocitos del donante y aceptaban trasplantes de piel del ratón donante de leucocitos, pero no de otro tipo de ratón. Por tanto, la tolerancia adquirida dependía del quimerismo leucocitario.

El concepto de microquimerismo natural (estado en el que células alogénicas hematopoyéticas coexisten con células del receptor) que aparece después del trasplante de órganos sólidos, fue sugerido por observaciones clínicas en las que el receptor de un riñon de un donante con pruebas cutáneas positivas adquiría dicha positividad que era negativa antes del trasplante (75). En 1992 Starzl y cols. (76) describieron un bajo nivel de leucocitos del donante en receptores humanos de riñon e hígado hasta 30 años antes. Starzl sugirió que la respuesta mutua de leucocitos de donante y receptor coexistiendo, causaban agotamiento clonal seguido de deleción periférica clonal de las células alorreactivas y de las células $\mathrm{T}$ del donante (73). El fenómeno del microquimerismo se asoció con la existencia de tolerancia, pero se ha cuestionado posteriormente y actualmente se interpreta más como un consecuencia que como la causa de la tolerancia de los injertos (77).

El hígado tiene una gran población de células hematopoyéticas que migran después del trasplante, por lo que se piensa que ocasiona un mayor grado de microquimerismo de stem cell y leucocitos atípicos como las DC que inducen hiporrespuesta de los linfocitos $\mathrm{T}$ alorreactivos, pero este mecanismo tolerogénico es distinto al propuesto por Starzl (15).

\section{RESUMEN Y CONCLUSIONES}

El hígado tiene unas propiedades tolerogénicas particulares que le permiten ser aceptado espontáneamente en algunas especies animales. Este proceso de tolerancia espontánea es un proceso activo dependiente de la transferencia de leucocitos del donante transportados con el hígado. La migración dentro del sistema linfoide del receptor da lugar a una activación inmune precoz de los linfocitos del receptor con la sucesiva deleción por agotamiento. Un mecanismo muy importante en la inducción de tolerancia es la supresión de la respuesta alogénica por linfocitos $\mathrm{T}$ reguladores. El microquimerismo leucocita- 
rio ha sido cuestionado como un mecanismo primordial en el mantenimiento de tolerancia.

En el contexto clínico, será importante monitorizar diversos parámetros inmunológicos de forma sistemática después del trasplante, para poder identificar los fenotipos y quizás los polimorfismos genéticos que se asocian con la tolerancia del injerto. Actualmente existen diversos estudios en marcha que analizan este aspecto, dirigidos a conocer parámetros que en un paciente concreto nos permitan predecir si podrá ser tolerante a la retirada de inmunosupresión tras un periodo de adaptación al nuevo órgano trasplantado.

\section{BIBLIOGRAFÍA}

1. Roberts MS, Angus DC, Bryce CL, Valenta Z, Weissfeld L. Survival after liver transplantation in the United States: a disease-specific analysis of the UNOS database. Liver Transpl 2004; 10: 886-97.

2. Furukawa H, Todo S. Evolution of immunosuppression in liver transplantation: contribution of cyclosporine. Transplant Proc 2004; 36 : 274S-84S.

3. Scott LJ, McKeage K, Keam SJ, Plosker GL. Tacrolimus: a further update of its use in the management of organ transplantation. Drugs 2003; 63: 1247-97.

4. Calne RY, Sells RA, Pena JR, et al. Induction of immunological tolerance by porcine liver allografts. Nature 1969; 223: 472-4.

5. Qian S, Lu L, Li Y, et al. Apoptosis within spontaneously accepted mouse liver allografts: evidence for deletion of cytotoxic T cells and implications for tolerance induction. J Immunol 1997; 158: 4654-61.

6. Farges O, Morris PJ, Dallman MJ. Spontaneous acceptance of liver allografts in the rat. Analysis of the immune response. Transplantation 1994; 57: 171-7.

7. Mazariegos GV, Reyes J, Marino IR, et al. Weaning of immunosuppression in liver transplant recipients. Transplantation 1997; 63: 2439.

8. Devlin J, Doherty D, Thomson L, et al. Defining the outcome of immunosuppression withdrawal after liver transplantation. Hepatology 1998; 27: 926-33.

9. Pons JA, Yelamos J, Ramirez P, et al. Endothelial cell chimerism does not influence allograft tolerance in liver transplant patients after withdrawal of immunosuppression. Transplantation 2003; 75: 10457.

10. Takatsuki M, Uemoto S, Inomata Y, et al. Weaning of immunosuppression in living donor liver transplant recipients. Transplantation 2001; 72: 449-54.

11. Martínez OM, Rosen HR. Basic concepts in transplant immunology. Liver Transpl 2005; 11: 370-81.

12. Sánchez-Fueyo A, Strom TB. Immunological tolerance and liver transplantation. J Hepatol 2004; 41: 698-705.

13. Calne RY. Prope Tolerance: The future of organ transplantationfrom the laboratory to the clinic. Transplantation 2004; 77: 930-2.

14. Fung JJ. Toward tolerance: Lessons learned from liver transplantation. Liver Transpl Surg 1999; 5 (Supl. 1): S90-S97.

15. Bishop GA, McCaughan W. Immune activation is required for the induction of liver allograft tolerance: Implications for immunosuppressive therapy. Liver Transpl 2001; 7: 161-72.

16. Lafferty KJ, Prowse SJ, Simeonovic CJ. Immunobiology of tissue transplantation: A return to the passenger leukocyte concept. Ann Rev Immunol 1983; 1: 143-73.

17. Lechler R, Ng WF, Steinman RM. Dendritic cells in transplantationFriend or foe? Immunity 2001; 14: 357-68.

18. Hall BM. Cells mediating allograft rejection. Transplantation 1991; 51: 1141-51.

19. Shoskes DA, Word KJ. Indirect presentation of MHC antigens in transplantation. Immunol Today 1994; 15: 32-8.

20. Demetris AJ, Qian S, Sun H, et al. Early events in liver allograft rejection. Delineation of sites of simultaneous intragraft and recipient lymphoid tissue sensitization. Am J Pathol 1991; 138: 609-19.
21. Illigens BM, Yamada A, Fedoseyeva EV, et al. The relative contribution of direct andindirect antigen recognition pathways to the alloresponse and graft rejection depends upon the nature of the transplant. HumImmunol 2002; 63: 912-25.

22. Salama AD, Najafian N, Clarkson MR, Harmon WE, Sayegh MH. Regulatory CD25+T cells in human kidney transplant recipients. J Am Soc Nephrol 2003; 14: 1643-51.

23. Molina-González M, Ortiz A. Aloreconocimiento. En: Molina-Gonzalez M, Ortiz A editores. Biología de la inmunosupresión del trasplante de órganos. Barcelona: Novartis Farmacéutica S.A.; 2005. p. 105-35.

24. Abbas AK, Murphy KM, Sher A. Functional diversity of helper T lymphocytes. Nature 1996; 383: 787-93.

25 Sallusto F, MacKay CR, Lanzavecchia A. The role of chemokine receptors in primary, effector, and memory immune responses. Annu Rev Immunol 2000; 18: 593-620.

26. Carreno BM, Collins M. The B7 family of ligands and its receptors: new pathways for costimulation and inhibition of immuneresponses. Ann Rev Immunol 2002; 20: 29-53.

27. Quezada SA, Jarvinen LZ, Lind EF, Noelle RJ. CD40 / CD154 interactions at the interface of tolerance and immunity. Annu Rev Immunol 2004; 22: 307-28.

28. Krams SM, Egawa H, Quinn MB, Villanueva JC, Garcia-Kennedy R, Martinez OM. Apoptosis is a mechanism of cell death in liver allograft rejection. Transplantation 1995; 59: 621-5.

29. Tannapel A, Kohlhaw K, Ebelt J, et al. Apoptosis and the expression of Fas and Fas ligand (FasL) antigen in rejection and reinfection in liver allograft specimens. Transplantation 1999; 15: 1079-183.

30. Wick MJ, Leithauser F, Reimann J. The hepatic immune system. Crit Rev Immunol 2002; 22: 47-103.

31. Emoto M, Kaufmann SH. Liver NKT cells: an account of heterogeneity. Trends Immunol 2003; 24: 364-9.

32. Katz SC, Pillarisetty VG, Bleier JI, Shah AB, DeMatteo RP. Liver sinusoidal endothelial cells are insufficient to activate T cells. J Immunol 2004; 173: 230-5.

33. O'Farrelly C. Immunoregulation in the liver and its extrahepatic relevance. J Pediatr Gastroenterol Nutr 2004; 39(Supl .3): S727-8.

34. O'Connell JB, Renlund DG, Bristow MR, et al. Detection of allograft endothelial cells of recipient origin following ABO-compatible, nonidentical cardiac transplantation. Transplantation 1991; 51: 438-42.

35. Lagaaij EL, Cramer-Knijnenburg GF, van Kemenade FJ, et al. Endothelial cell chimerism after renal transplantation and vascular rejection. Lancet 2001; 357: 33-7.

36. Gao ZH, McAlister VC, Williams GM. Repopulation of liver endothelium by bone marrow-derived cells. Lancet 2001; 357: 932-3.

37. Starzl TE. The "privileged" liver and hepatic tolerogenicity. Liver Transp 2001; 7: 918-20.

38. Warren A, Le Couteur DG, Fraser R, Bowen DG, McCaughan GW, Bertolino P. T lymphocytes interact with hepatocytes through fenestrations in murine liver sinusoidal endothelial cells. Hepatology 2006; 44: 1182-90.

39. McAvoy EF, Kubes P. Holey endothelium: gateways for naïve $\mathrm{T}$ cell activation. Hepatology 2006; 44: 1083-5.

40. Calne R, Sells RA, Pena JR, et al. Induction of immunological tolerance by porcine liver allografts. Nature 1969; 223: 472-6.

41. Kamada N, Calne RY. A surgical experience with five hundred thirty liver transplants in the rat. Surgery 1983; 93: 64-9.

42. Qian S, Demetris AJ, Murase N, Rao AS, Fung JJ, Starzl TE. Murine liver allograft transplantation: tolerance and donor cell chimerism. Hepatology 1994; 19: 916-24.

43. Kamada N, Wight DG. Antigen-specific immunosuppression induced by liver transplantation in the rat. Transplantation 1984; 38 : 217-21.

44. Wang C, Sun J, Li L, Wang L, Dolan P, Sheil AGR. Conversion of pancreas allograft rejection to acceptance by liver transplantation. Transplantation 1997; 65: 188-92.

45. Donaldson PT, Thomson LJ, Heads A, et al. IgG donor-specific cross-matches are not associated with graft rejection or poor graft survival after liver-transplantation-An assessment by cytotoxicity and flowcytometry. Transplantation 1995; 60: 1016-23.

46. Doran TJ, Geczy AF, Painter D, et al. Large, single center investigation of the immunogenetic factors affecting liver transplantation. Transplantation 2000; 69: 1491-8. 
47. Rasmussen A, Davies HFS, Jamieson NV, Evans DB, Calne RY. Combined transplantation of liver and kidney from the same donor protects the kidney from rejection and improves kidney graft-survival. Transplantation 1995; 59: 919-21.

48. Reding R, Davies HFS. Revisiting liver transplant immunology: From the concept of immune engagement to the Dualistic pathway paradigm. Liver Transpl 2004; 10: 1081-6.

49. Molina-Gonzalez M, Ortiz A. Tolerancia inmunológica. En: MolinaGonzalez M, Ortiz A editores. Biología de la inmunosupresión del trasplante de órganos. Barcelona: Novartis Farmacéutica S.A.; 2005. p. 180-98.

50. Rodríguez-Barbosa JI, Zhao Y, Barth R, et al. Enhanced CD4 reconstitution by grafting neonatal porcine tissue in alternative locations is associated with donor-specific tolerante and suppession of preexisting xenoreactive $\mathrm{T}$ cells. Transplantation 2001; 72: 1223-31.

51. Sykes M. Mixed chimerism and transplant tolerance. Immunity 2001; 14: 417-24.

52. Cobbold S, Waldmann H. Infectious tolerance. Curr Opin Immunol 1998; 10: 518-24.

53. Graca L, Cobbold SP, Waldmann H. Identification of regulatory $\mathrm{T}$ cells in tolerated allografts. J Exp Med 2002; 195: 1641-6.

54. Monaco AP, Clarck AW, Wood ML, et al. Possible active enhancement of a human cadaver renal allograft with antilymphocyte serum (ALS) and donor bone marrow: Case report of an initial attempt. Surgery 1976; 79: 384 .

55. Fontes P, Rao AS, Demetris AJ, et al. Bone marrow augmentation of donor-cell chimerism in kidney, liver, heart, and pancreas islet transplantation. Lancet 1994; 344: 151.

56. Pauw L, Toungouz, Goldman M. Infusion of donor-derived hematopoietic stem cells in organ transplantation: clinical data. Transplantation 2003; 75: 46S-9S.

57. Bishop GA, Sharland AF, McCaughan GW. High-dose/activationassociated tolerance model for allografts: Lessons from spontaneous tolerance of transplanted livers. Curr Opin Organ Transplant 1999; 4: 58-64.

58. Rifle G, Hervé P. Regulatory (suppessor) T cells in peripheral allograft tolerance and graft-versus-host reaction. Transplantation 2004; 77 (Supl. 1): S5.

59. Saas PH, Kleinclauss F, Tiberghien P. Immune regulation and transplantation. An exciting challenge. Transplantation 2004; 77 (Supl. 1): S38-S40.

60. Graca L, Thompson S, Lin CY, Adams E, Cobbold SP, Waldmann $\mathrm{H}$. Both CD4(+)CD25(+) and CD4(+)CD25(-) regulatory cells mediate dominant transplantation tolerance. J Immunol 2002; 168: 555865 .

61. Sakaguchi S, Sakaguchi N, Asano M, Itoh M, Toda M. Immunologic self-tolerance maintained by activated $\mathrm{T}$ cells expressing IL-2 recep- tor alpha-chains (CD25). Breakdown of a single mechanism of selftolerance causes various autoimmunediseases. J Immunol 1995; 155: 1151-64.

62. Hori S, Nomura T, Sakaguchi S. Control of regulatory T cell development by the transcription factor FOXP3. Science 2003; 1057-61.

63. Taams L, Vukmanovic-Stejic M, Salmon M, Akbar A. Immnune regulation by $\mathrm{CD} 4+\mathrm{CD} 25+$ regulatory $\mathrm{T}$ cells: implications for transplantation tolerance. Transplant Immnunol 2003; 11: 277-85.

64. Jonuleit H, Schmitt E, Kakirman H, Stassen M, Knop J, Enk AH. Infectious tolerance: human $\mathrm{CD} 25 \mathrm{q}$ regulatory $\mathrm{T}$ cells convey suppressor activity to conventional CD4q T helper cells. J Exp Med 2002; 196: 255-60.

65. Dieckmann D, Plottner H, Berchtold S, Berger T, Schuler G. Ex vivo isolation and characterization of $\mathrm{CD} 4 \mathrm{qCD} 25 \mathrm{q} \mathrm{T}$ cells with regulatory properties from human blood. J Exp Med 2001; 193: 1303-10.

66. Jonuleit H, Schmitt E, Schuler G, Knop J, Enk AH. Induction of interleukin 10-producing, non-proliferating $\mathrm{CD} 4 \mathrm{q} \mathrm{T}$ cells with regulatory properties by repetitive stimulation with allogeneic immature human dendritic cells. J Exp Med 2000; 192: 1213-22.

67. Li Y, Koshiba T, Yoshizawa A, et al. Analyses of peripheral blood mononuclear cells in operational tolerance after pediatric living donor liver transplantation. Am J Transplant 2004; 4: 2118-25.

68. Martínez-Llordella M, Puig-Pey I, Orlando G, et al. Multiparameter immune profiling of operational tolerance in liver transplantation. Am J Transplant 2007; 7: 309-19.

69. Yamazaki S, Iyoda T, Tarbell K, et al. Direct expansion of functional $\mathrm{CD} 25+\mathrm{CD} 4+$ regulatory $\mathrm{T}$ cells by antigen-processing dendritic cells. J Exp Med 2003; 198: 235-47.

70. Abe M, Thomson A. Influence of immunosuppressive drugs on dendritic cells. Transplant Immunol 2003; 11: 357-65.

71. Robinson SP, Patterson S, English N, Davies D, Knight SC, Reid CD. Human peripheral blood contains two distinct lineages of dendritic cells. Eur J Immunol 1999; 29: 2769-78.

72. Mazariegos GV, Zahorchak AF, Reyes J, et al. Dendritic cell subset ratio in peripheral blood correlates with successful withdrawal of immunosuppression in liver transplantation. Am J Transplant 2003; 3: 689-96.

73. Starzl TE. Chimerism and tolerance in transplantation. PNAS 2004; 101 (Supl. 2): 14607-14.

74. Billingham RE, Brent L, Medawar PB. Activity acquired tolerance of foreing cells. Nature 1953; 172: 603-6.

75. Fung JJ. Toward tolerance: Lessons learned from liver transplantation: Liver Transpl Surg 1999; 5 (Supl. 1): S90-97.

76. Starzl TE, Demetris AJ, Trucco M, et al. Systemic chimerism in human female recipients of male livers. Lancet 1992; 340: 876-7.

77. Wood K, Sachs DH. Chimerism and transplantation tolerance: cause and effect. Immunol Today 1996; 17: 584-7. 